\title{
COMMENT
}

\section{Subsurface activity of benthic foraminifera}

\author{
L. Moodley*, P. M. J. Herman, J. J. Middelburg, C. H. R. Heip
}

Netherlands Institute of Ecology, Centre for Estuarine and Coastal Ecology (NIOO-CEMO), Vierstraat 28, 4401 EA, Yerseke, The Netherlands

In a recent paper Alve \& Bernhard (1995) tested the hypothesis that dissolved oxygen concentration drives foraminiferal vertical distribution within the sediment. The study addresses an important aspect of foraminiferal ecology, the conclusions of which will have great ecological and paleoecological implications. Vertical distributions of foraminiferal assemblages within the sediment were followed in boxcore mesocosms under varying concentrations of dissolved oxygen in the overlying water. Opposing physical or biological displacement (e.g. Buzas 1977, Collison 1980, Moodley 1990), Alve \& Bernhard concluded that dissolved oxygen drives foraminiferal vertical distribution within sediments and that foraminiferal species track and select a particular oxygen regime regardless of its position with respect to the sediment-water interface and irrespective of bioturbation activity. In our opinion, these conclusions cannot be drawn on the basis of Alve \& Bernhard's data set because: (1) oxygen was not directly measured in the sediment, (2) their choice of reference level (depth above which $85 \%$ of the specimens $>63 \mu \mathrm{m}$ were found) is subjective, and (3) differences between control and experimental mesocosms were not significant given the limited replication. Their data set does however contain important and unique information about benthic foraminiferal tolerance for dysoxic and anoxic conditions.

Alve \& Bernhard manipulated the oxygen concentration in the water column and not that in the sediment. In coastal sediment with a relatively high organic carbon content, oxygen penetration depth is usually limited to a few mm (e.g. Revsbech et al. 1980, Rasmussen \& Jorgensen 1992) whereas subsurface distribution of foraminifera are usually studied at the $\mathrm{cm}$ scale (up to $10-25 \mathrm{~cm}$ ) rather than $\mathrm{mm}$. Therefore oxygen cannot play a direct role in the subsurface distribution of foraminifera at depths more than a few $\mathrm{mm}$.

•E-mail:moodley@cemo.nioo.knaw.nl
Alve \& Bernhard chose to present their data and draw their conclusions based on the depth above which $85 \%$ of the stained individuals occurred. This is not $85 \%$ of the total population, but $85 \%$ of the specimens larger than $63 \mu \mathrm{m}$. Although the use of a $63 \mu \mathrm{m}$ sieve is consistent with most foraminiferal studies, utilization of only $85 \%$ of this size fraction for analysis is subjective.

The few (pseudo) replicate cores presented for the experimental conditions indicate that variability is high, and it can be questioned if the changes in vertical distribution are significant. We analysed the available data (raw density data from Alve \& Bernhard's Table 2) with a nested ANOVA, separating variation between treatments from variation between cores within a treatment. The basic variable in this statistical procedure is (log-transformed) depth at which an individual occurs. The analyses were performed separately for each sampling event, since treatments (average oxygen concentration in the water prior to sampling) differed for each event. The results (Table 1) consistently show that the replicate cores contribute significantly to the variation, but that treatment does not add significantly to the depth distribution. We conclude that the variation in the data does not support the conclusions drawn by Alve \& Bernhard. ${ }^{1}$

However, when the data set is viewed in its totality, an important result of Alve \& Bernhard's study that they did not discuss is that all species survived mod-

\footnotetext{
${ }^{1}$ After information exchange (Moodley et al., Alve \& Bernhard, MEPS editor), the following clarification was added by Moodley et al. to their original manuscript:

'It should be noted, however, that the power of the experiment set-up to reject the null hypothesis (no effect of treatments) and therefore to accept the alternative hypothesis (oxygen regime affects depth distribution) is very limited Thus, even if the analysis shows no support for Alve \& Bernhard's conclusions, it should not be considered in itself as a proof that oxygen does not affect depth distribution.'
} 
Table 1. Results of nested ANOVA analysis of depth distribution of foraminifera at different sampling events. $F(T: C)$ tests the significance of treatment variation over variation between cores within treatments, $F(C: E)$ tests significance of cores within treatment over error variation. NS: $p>0.05, \cdots p<0.001$

\begin{tabular}{|c|c|c|c|c|c|c|c|c|}
\hline \multirow[t]{2}{*}{$\begin{array}{l}\text { Sampling } \\
\text { event }\end{array}$} & \multicolumn{2}{|c|}{ Treatment } & \multicolumn{2}{|c|}{$\begin{array}{c}\text { Cores within } \\
\text { treatment }\end{array}$} & \multicolumn{2}{|c|}{$\begin{array}{l}\text { Errors within } \\
\text { cores }\end{array}$} & \multirow[t]{2}{*}{$F(\mathrm{~T}: \mathrm{C})$} & \multirow[t]{2}{*}{$F(C: E)$} \\
\hline & MS & $\mathrm{df}$ & MS & df & MS & $\mathrm{df}$ & & \\
\hline 2 & 0.285 & 1 & 1.142 & 1 & 0.061 & 1767 & $0.250^{\mathrm{NS}}$ & $18.661 \cdots$ \\
\hline 5 & 2.173 & 1 & 1.855 & 1 & 0.065 & 2488 & $1.171^{\mathrm{NS}}$ & $28.344^{\cdots}$ \\
\hline 6 & 66.853 & 1 & 10.949 & 1 & 0.096 & 2123 & $6.106^{\mathrm{NS}}$ & $113.908 \cdots$ \\
\hline 7 & 4.987 & 1 & 6.005 & 1 & 0.046 & 3805 & $0.830^{\mathrm{NS}}$ & $131.747 \cdots$ \\
\hline
\end{tabular}

demonstrates that these benthic foraminifera have extremely low oxygen requirements and even flourish under short-term anoxia and that the direct role of oxygen in the subsurface activity of benthic foraminifera may be grossly overestimated.

Acknowledgements. Karline Soetaert is gratefully acknowledged for critically reviewing the manuscript.

\section{LITERATURE CITED}

erate to severe dysoxic conditions $\left(\left[\mathrm{O}_{2}\right]=2\right.$ to $\left.0.7 \mathrm{ml} \mathrm{l}^{-1}\right)$ for $93 \mathrm{~d}$ and suboxic conditions $\left(\left[\mathrm{O}_{2}\right]=0.16 \mathrm{ml} \mathrm{l}^{-1}\right)$ for $34 \mathrm{~d}$. Considering that the investigated sediments were fine-grained with a relatively high organic carbon content $(2.9$ to $3.1 \%)$, bottom waters with only $0.16 \mathrm{ml} \mathrm{l}^{-1}$ oxygen will have induced totally anoxic conditions close to the sediment-water interface (within the scale of micrometers) if not at the sediment boundary layer. This in turn would mean that all species survived anoxic conditions for at least $34 \mathrm{~d}$. This indicates that many species of benthic foraminifera are not affected by and cope rather well with dysoxic and anoxic conditions (Josefson \& Widbom 1988, Bernhard \& Reimers 1991, Moodley \& Hess 1992, Bernhard 1993). Consequently, all species encountered in their study can be classified as being highly tolerant to dysoxic and suboxic/anoxic conditions. During the long duration of Alve \& Bernhard's experiment (246 d) reproduction took place (as evidenced by the presence of juveniles) and their epifaunal species (i.e. preferring higher oxygen concentration) Bulimina marginata also reproduced under dysoxic and suboxic/anoxic conditions. Their study is therefore the first record of reproduction under dysoxic or suboxic/anoxic conditions. It clearly
Alve E, Bernhard JM (1995) Vertical migratory response of benthic foraminifera to controlled oxygen concentrations in an experimental mesocosm. Mar Ecol Prog Ser 116:137-151

Bernhard JM (1993) Experimental and field evidence of Antarctic foraminiferal response to anoxia and hydrogen sulfide. Mar Micropaleontol 20:203-213

Bernhard JM, Reimers CE (1991) Benthic foraminiferal population fluctuations related to anoxia: Santa Barbara Basin. Biogeochemistry 15:203-213

Buzas MA (1977) Vertical distribution of foraminifera in the Indian River, Florida. J Foraminiferal Res 7:234-237

Collison P (1980) Vertical distribution of foraminifera off the coast of Northumberland, England. J Foraminiferal Res 10:75-78

Josefson AB, Widbom B (1988) Differential response of benthic macrofauna and meiofauna to hypoxia in the Culmar Fjord basin. Mar Biol 100:31-40

Moodley L (1990) Southern North Sea seafloor and subsurface distribution of living benthic foraminifera. Neth J Sea Res 27:57-71

Moodley L. Hess C (1992) Tolerance of infaunal benthic foraminifera for low and high oxygen concentrations. Biol Bull 183:94-98

Rasmussen H, Jørgensen BB (1992) Microelectrode studies of seasonal oxygen uptake in a coastal sediment: role of molecular diffusion. Mar Ecol Prog Ser 81:289-303

Revsbech NP, Sorenson J, Blackburn TH, Lumholt JP (1980) Distribution of oxygen in marine sediments measured with microelectrodes. Limnol Oceanogr 25:403-411 